\title{
Editorial
}

Journal of Innate

Immunity

Published online: December 5, 2013

DOI: $10.1159 / 000357283$

\section{Immunological Memory in Innate Immunity}

\author{
Mihai G. Netea \\ Department of Internal Medicine and Nijmegen Institute for Infection, Inflammation and Immunity, \\ Radboud University Medical Center, Nijmegen, The Netherlands
}

Traditionally, vertebrate immune responses have been divided into innate responses, which are rapid, nonspecific and incapable of building immune memory, and adaptive responses, which develop more slowly, are highly specific, and build a long-term immunological memory. While the nonspecificity of innate immune responses has been challenged by the discovery of pattern recognition receptors, recent studies suggest that adaptive characteristics are also found in cells of the innate immune system [1]. This concept has been supported by studies in plants, invertebrates, and mammals, with a paradigm shift in our understanding of host defense, and mounting evidence for innate immune memory, i.e. increased responses to secondary infections [2].

The adaptive characteristics of innate immune memory are exerted at several levels. Earlier studies have shown that an enhanced state of innate immunity can be triggered by certain infections or vaccinations, which are mediated by prototypical innate immune cells such as natural killer cells and monocytes/macrophages. Changes at the level of membrane receptors on the cell surface of natural killer cells [3] or epigenetic reprogramming of monocytes and macrophages through histone modifications [4] are some of the mechanisms mediating innate immune memory, and this process has been also termed

\section{KARGER}

(๑) 2013 S. Karger AG, Basel

1662-811X/13/0062-0117\$38.00/0

E-Mail karger@karger.com

www.karger.com/jin 'trained immunity'. Trained immunity provides protection against reinfection in a T-/B-cell-independent manner, with nonspecific potentiation of inflammatory reactions and antimicrobial mechanisms playing a central role in these effects [4].

The current issue of the Journal of Innate Immunity presents a series of studies that shed additional light on important aspects of the adaptive properties of innate immunity. One of the most important groups of organisms in which innate immune memory has been reported are insects. In a study in Anopheles gambiae mosquitoes, Ramirez et al. [5] describe the cellular and molecular pathways responsible for the priming of the hematocytes of the insect during infections with plasmodia. The role of innate immune cells for the capacity of innate host defense to adapt to stimuli has been previously stated both in insects and vertebrates [2]. An additional argument for adaptive effects in innate immune cells is provided by the study of Short et al. [6], which demonstrates that innate immune stimulation with a microbial ligand, in this case lipopolysaccharide, decreases susceptibility to influenza. Nonspecific effects of lipopolysaccharides on antiviral type I interferons are involved in these effects. In addition to effects mediated through cellular mechanisms, generation of natural xenoantibodies also induces 
nonspecific effects during infection, as shown by PerezCruz et al. [7]. Finally, nonspecific adaptive characteristics of innate immunity are shown to occur and to be sustained for at least 1 year after vaccination in humans. In their study, Kleinnijenhuis et al. [8] demonstrate the strong induction of both trained immunity and heterologous Th1/Th17 responses after BCG vaccination in healthy volunteers.
In conclusion, these studies are a showcase of the various aspects through which innate immune responses can mount nonspecific adaptive traits that induce protective responses during reinfection of the host. They contribute to this emerging new field that promises to represent a paradigm change in immunity, resulting in a better understanding of host defense and eventually the development of novel immunotherapeutic approaches in the future.

\section{References}

1 Bowdish DM, Loffredo MS, Mukhopadhyay S, Mantovani A, Gordon S: Macrophage receptors implicated in the 'adaptive' form of innate immunity. Microbes Infect 2007;9: 1680-1687.

-2 Netea MG, Quintin J, van der Meer JW: Trained immunity: a memory for innate host defense. Cell Host Microbe 2011;9:355-361.

$>3$ Sun JC, Beilke JN, Lanier LL: Adaptive immune features of natural killer cells. Nature 2009;457:557-561.
-4 Quintin J, Saaed S, Martens JHA, Giamarellos-Bourboulis EJ, Ifrim DC, Logie C, Jacobs L, Jansen T, Kullberg BJ, Wijmenga C, Joosten LA, Xavier RJ, van der Meer JW, Stunnenberg HG, Netea MG: Candida albicans infection affords protection against reinfection via functional reprogramming of monocytes. Cell Host Microbe 2012;12:223-232.

5 Ramirez JL, Garver LS, Brayner FA, Alves LC, Rodrigues J, Molina-Cruz A, Barillas-Mury C: The role of hemocytes in Anopheles gambiae antiplasmodial immunity. J Innate Immun 2014;6:119-128.

6 Short KR, Vissers M, de Kleijn S, Zomer AL, Kedzierska K, Grant E, Reading PC, Hermans PWM, Ferwerda G, Diavatopoulos DA: Bacterial lipopolysaccharide inhibits influenza virus infection of human macrophages and the consequent induction of CD8+ T cell immunity. J Innate Immun 2014;6:129-139.
Perez-Cruz M, Costa C, Mañez R: Boosted rat natural xenoantibodies cross-react with $\mathrm{En}$ terococcus faecalis by targeting melibiose and L-rhamnose. J Innate Immun 2014;6:140151 .

$>8$ Kleinnijenhuis J, Quintin J, Preijers F, Benn CS, Joosten LAB, Jacobs C, van Loenhout J, Xavier RJ, Aaby P, van der Meer JWM, van Crevel R, Netea MG: Long-lasting effects of BCG vaccination on both heterologous Th1/ Th17 responses and innate trained immunity. J Innate Immun 2014;6:152-158. 